\title{
Investigation of Charge Transfer Complexes Formed between Mirtazapine and Some $\pi$-Acceptors
}

\author{
Hulya Demirhan, Mustafa Arslan, Mustafa Zengin, and Mustafa Kucukislamoglu \\ Chemistry Department, Faculty of Arts and Sciences, Sakarya University, 54187 Sakarya, Turkey \\ Correspondence should be addressed to Mustafa Arslan; marslan@sakarya.edu.tr
}

Received 22 June 2012; Accepted 3 August 2012

Academic Editor: Shin ichi Morita

Copyright (c) 2013 Hulya Demirhan et al. This is an open access article distributed under the Creative Commons Attribution License, which permits unrestricted use, distribution, and reproduction in any medium, provided the original work is properly cited.

Charge transfer complexes (CTC) of mirtazapine with tetracyanoethylene (TCNE), 2,3-dichloro-5,6-dicyano-p-benzoquinone (DDQ), and tetracyanoquinodimethane (TCNQ) have been studied spectrophotometrically in dichloromethane at room temperature. The stoichiometries of the complexes were found to be $1: 1$ ratio by the Job Method between mirtazapine and the acceptors. The equilibrium constants and thermodynamic parameters of the complexes were determined by the Benesi-Hildebrand and Van't Hoff equations. Mirtazapine in pure and dosage form was applied in this study. The results indicate that the formation constants for the complexes depend on the nature of electron acceptors and donor. And also the spectral studies of the complexes were determined by FT-IR and NMR spectroscopy.

\section{Introduction}

Mirtazapine(1,2,3,4,10,14b-hexahydro-2-methylpyrazino[2, 1-a]pyrido[2,3-c][2]benzazepine) is the piperazino-azepine group of compound which has antidepressant therapeutic effects. It is a tetracyclic noradrenergic and specific serotonergic antidepressant which act as an antagonist of central presynaptic $\alpha 2$-adrenergic autoreceptors and heteroreceptors as well as a potent antagonist of postsynaptic 5-HT2 and 5-HT3 receptors [1-3]. It also apparently causes a net activation of primarily 5-HT1A receptors [4]. Furthermore, mirtazapine is an antihistaminergic agent with a high affinity for histamine $\mathrm{H} 1$ receptors and manifests a very low affinity for dopaminergic receptors [5], and the chemical structure of mirtazapine is shown in Scheme 1.

Charge transfer complexation is an important phenomenon in biochemical and bioelectrochemical energy transfer process [6]. The electron donor-acceptor interactions have been widely studied spectrophotometrically in the determination of the drug based on the CT Complexes formation with some $\pi$-acceptors [7-9]. The interactions of the charge transfer complexes are well known in many chemical reactions such as addition, substitution, and condensation $[10,11]$. The molecular interactions between electron donors and acceptors are generally associated with the formation of intensely coloured charge transfer complexes, which absorb radiation in the visible region [12]. Electron donor-acceptor CT interactions are also important in the field of drugreceptor binding mechanism [13], in solar energy storage [14], and in surface chemistry [15] as well as in many biological fields [16]. On the other hand, the CT-reactions of $\pi$-acceptors have successfully been utilized in pharmaceutical analysis [17] and non-linear optical properties $[18,19]$.

In continuation of our studies of charge transfer conplexes [20-22], this paper reports simple, direct, and sensitive spectrophotometric method for the determination of mirtazapine with some $\pi$-acceptors such as TCNE, DDQ, and TCNQ. Mirtazapine was used as drug both in dosage and pure form. Stoichiometries, equilibrium constants, and thermodynamic parameters of the complexes were determined. And also, the CTC of the mirtazapine- $\pi$-acceptors were determined by FT-IR and NMR spectroscopy.

\section{Experimental}

2.1. Materials and Spectral Measurements. The materials used in this study were obtained from local suppliers; TCNE (Merck), DDQ (Merck), TCNQ (Merck), mirtazapine tablets (Remeron Drage, Santa Farma Drug Company, Turkey). 


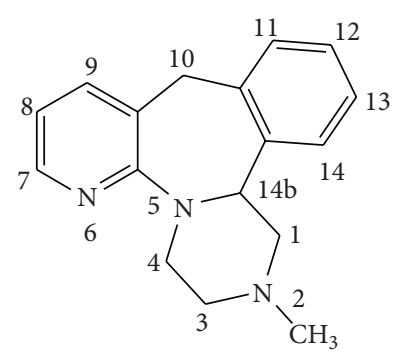

Scheme 1: Chemical structure of mirtazapine.

Dichloromethane (Merck) was redistilled before using. All laboratory reagents were freshly prepared.

The electronic absorption spectra were recorded in the region 900-200 $\mathrm{nm}$ using Shimadzu 2401 UV-Vis spectrophotometer with a quartz cell of $1.0 \mathrm{~cm}$ path length. The infrared spectra of the isolated complexes and the reactants were measured as a solid sample on Shimadzu IR Prestige 21 model FT-IR. ${ }^{1}$ HNMR spectra were obtained by Varian $300 \mathrm{MHz}$ Infinity Plus using $\mathrm{CDCl}_{3}$ as the solvent.

\subsection{Preparation of Standard Solutions}

2.2.1. Acceptors. A stock solution of acceptors at a concentration of $1 \times 10^{-2} \mathrm{M}$ was prepared in different volumetric flasks by dissolving 12.8, 22.7, 20.4 mg of TCNE, DDQ, and TCNQ powder accurately weighed in dichloromethane and making up to $10 \mathrm{~mL}$ with the same solvent.

2.2.2. Mirtazapine. A standard solution of mirtazapine was prepared by dissolving $26.5 \mathrm{mg}$ of pure mirtazapine in a $10 \mathrm{~mL}$ volumetric flask using dichloromethane.

2.2.3. Absorption Spectra. A $2 \mathrm{~mL}$ volume of mirtazapine and acceptors were scanned separately through a UV-Vis spectrophotometer to their wavelength of maximum absorption. When $2 \mathrm{~mL}$ of acceptor solution and $2 \mathrm{~mL}$ of donor solution were mixed, a color charge transfer complex was formed. The wavelength of maximum absorption of the resulting solution was determined by the spectrophotometer.

2.3. Stoichiometries of the Complexes. Job's method of continuous variations was used to determine the stoichiometries of the complexes [23, 24]. Master solutions of equimolar concentrations of the drug and acceptor in dichloromethane were used in this experiment. Aliquots of the solutions were varied alternately from 0.2 to $0.8 \mathrm{~mL}$ for donor and acceptor solutions to hold the total volume at $1 \mathrm{~mL}$ in the cuvette by using a $1 \mathrm{~mL}$ pipette. Average absorbances were obtained from three runs on the same sample and average values at $790-800 \mathrm{~nm}$ were subtracted from the average values at the maxima. The complex for the each reaction mixture was kept at 10 minutes at room temperature to form stable complexes before scanning.
2.4. Determination of Equilibrium Constants. Benesi-Hildebrand equation [25] was used for the determination of the equilibrium constants of the complexes. $0.53 \mathrm{mg}$ of mirtazapine was weighed in the cuvette and added in $2 \mathrm{~mL}$ of $3 \times 10^{-4} \mathrm{M}$ acceptor solution. Then, each time $0.2 \mathrm{~mL}$ of $3 \times 10^{-4} \mathrm{M}$ acceptor solution was added in cuvette and absorption values were obtained at indicated wavelengths. After adding each time, waited for $10 \mathrm{~min}$ for getting stable complex. The UV-Vis spectrum was measured after each addition of $0.2 \mathrm{~mL}$ of solution. About 10 dilutions were run with each sample.

2.5. Thermodynamic Constants. The thermodynamic constants of the complexes between donor and acceptor were determined by Van't Hoff equation. $1.5 \mathrm{~mL}$ of $10^{-2} \mathrm{M}$ mirtazapine and $1.5 \mathrm{~mL}$ of $10^{-2} \mathrm{M}$ of acceptor from the stock solution were mixed and absorbances were obtained at the five different temperatures such as $7,14,21,28$, and $35^{\circ} \mathrm{C}$. The thermodynamic parameters $\left(\Delta H^{\circ}, \Delta S^{\circ}\right.$ and $\left.\Delta G^{\circ}\right)$ were calculated by plotting $\ln (\mathrm{Abs}) / \varepsilon-\ln \left(\mathrm{D}_{\mathrm{o}}-\mathrm{Abs} / \varepsilon\right)\left(\mathrm{A}_{\mathrm{o}}-\mathrm{Abs} / \varepsilon\right)$ versus $1 / T\left({ }^{\circ} \mathrm{K}\right)$.

2.6. Mirtazapine Tablets. Forty Remeron tablets were finely powdered and amount equivalent to $40 \mathrm{mg}$ mirtazapine was accurately weighed. Transferred to a beaker containing $10 \mathrm{~mL}$ of dichloromethane and shaken for a while to dissolve the drug. Then, the solution was filtered to the $10 \mathrm{~mL}$ of volumetric flask and filled by dichloromethane to provide a theoretical $10^{-2} \mathrm{M}$ solution of mirtazapine. $2 \mathrm{~mL}$ of acceptor solution was added to $2 \mathrm{~mL}$ of drug solution. The absorbance was determined 418,708 , and $850 \mathrm{~nm}$ with TCNE, DDQ, and TCNQ, respectively.

\section{Results and Discussion}

The absorption spectra of solutions containing donor and acceptors together exhibit new absorptions at longer wavelength than either the donors $(\lambda<350 \mathrm{~nm})$ or the acceptors $(\lambda<450 \mathrm{~nm})$ alone.

A solution of TCNE, DDQ, and TCNQ in dichloromethane had cream, orange, and yellowish-green color with the maximum wavelength lower than $450 \mathrm{~nm}$, respectively. Yellow, brick red, and dark green colors were obtained on the interaction of TCNE, DDQ, and TCNQ acceptor solutions, respectively. The colorless solution of mirtazapine in dichloromethane was changed to colored solution, and it mentions a charge transfer complex formation. Scanning of the complex in the visible range between 400 and $900 \mathrm{~nm}$ showed the maximum peaks at 418, 708, and $850 \mathrm{~nm}$, respectively, and the spectra are shown in Figure 1.

During the complexation, charge transfer transitions occur with the excitation of an electron from HOMO of the donor to LUMO of the acceptor. This is shown schematically in Scheme 2 in which $h v_{\mathrm{CT}}$ depicts the energy of the CT transitions. The lowest energy CT transition will involve promotion of an electron residing in the high occupied molecular orbital (HOMO) of the donor to the acceptor 


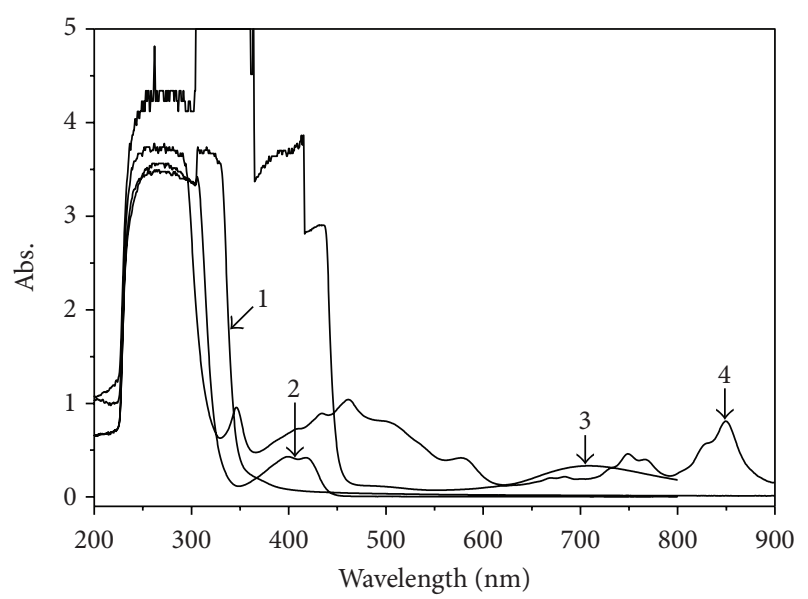

FIGURE 1: Mirtazapine (1) and charge transfer complexes of mirtazapine with TCNE (2), DDQ (3), and TCNQ (4) in dichloromethane at $21^{\circ} \mathrm{C}$.

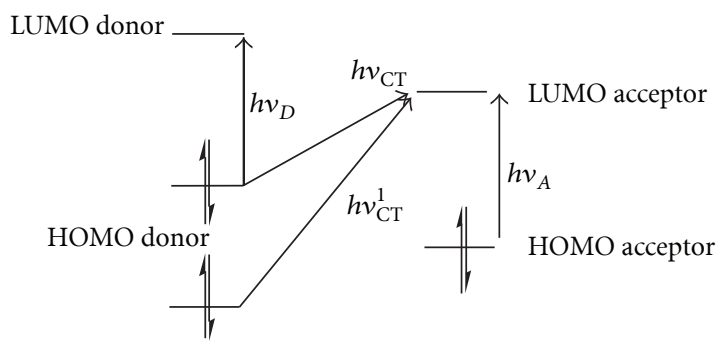

SCHEME 2: Charge transfer transitions for HOMOs of the donor and LUMOs of the acceptor.

as shown for $h v_{\mathrm{CT}}$. Charge transfer transitions involving electrons in lower energy orbitals also are possible and would result in higher energy CT transitions as shown $h v_{\mathrm{CT}}^{1}$.

The interactions between mirtazapine and $\pi$-acceptors give $n-\pi^{*}$ transitions and form radical ion pairs, such as radical cation and radical anions. Charge transfer transition reaction is shown in Scheme 3.

The stoichiometries of the complex formation were determined by Job's method of continuous variation and indicated as $1: 1$ ratio shown in Figure 2.

The formation constants $\left(K_{\mathrm{CT}}\right)$ and molar extinction coefficient $\left(\varepsilon_{\mathrm{CT}}\right)$ values of mirtazapine- $\pi$-acceptors (TCNE, DDQ, TCNQ) CT complexes were studied in dichloromethane at $21^{\circ} \mathrm{C}$. The Benesi-Hildebrand equation was used for the calculations [25] and shown below:

$$
\frac{\left[A_{0}\right]}{\mathrm{ABS}}=\frac{1}{K \in\left[D_{0}\right]}+\frac{1}{\varepsilon},
$$

where $\left[D_{0}\right]$ is the concentration of the donor; $\left[A_{0}\right]$ is the concentration of the acceptor; ABS is the absorbance of the complex; $\varepsilon$ is the molar absorptivity for the complex; $K$ is the association constant of the complex.

Straight lines were obtained (Figure 3 ) by plotting the values $\left[A_{0}\right] /$ ABS versus $1 /[D]$ and the results shown in Table 1 revealed that the $K$ values of charge transfer complexes with

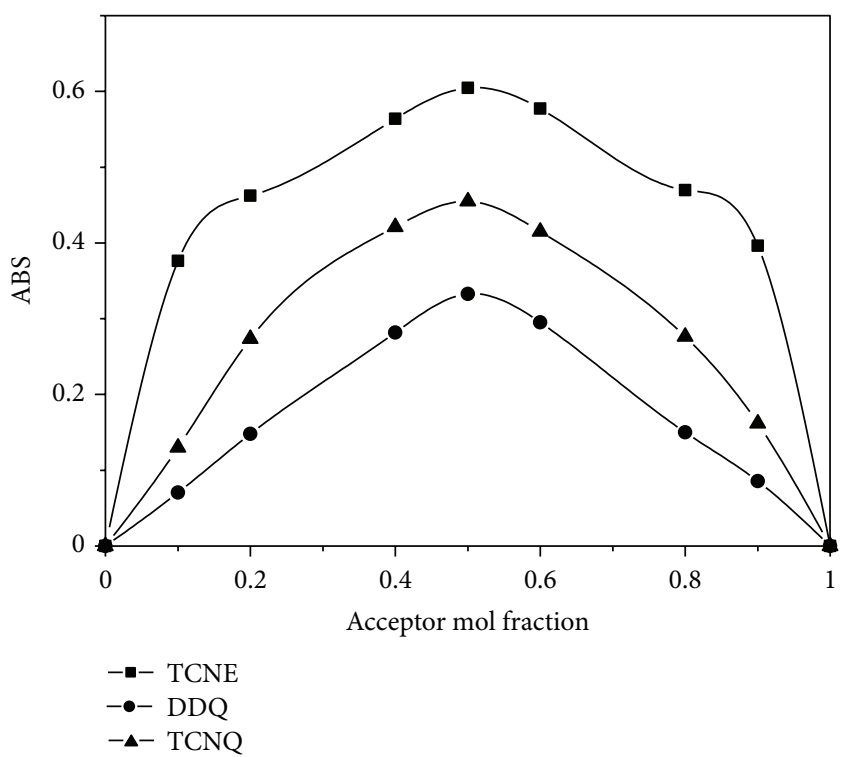

FIGURE 2: The plot of Job's method for mirtazapine with TCNE (+), $\operatorname{DDQ}(\Delta)$, and TCNQ $(\mathrm{O})$.

TCNQ are higher than the corresponding values with TCNE and DDQ. This is consistent with the decrease in electron affinity of TCNE relative to DDQ. On the other hand, the results indicate that the electron accepting ability of TCNQ is higher than that of DDQ and also electron accepting ability of DDQ is higher than that of TCNE. TCNQ has four strong electron withdrawing groups in conjugation with an aromatic ring which causes high delocalization leading to an increase in the lewis acidity of the acceptor. The results are compatible with the literature [26].

Thermodynamic parameters $\left(\Delta H^{\circ}, \Delta S^{\circ}\right)$ of the CT complexes of mirtazapine with TCNE, TCNQ, and DDQ were determined from Van't Hoff and Beer-Lambert equations

$$
\ln \frac{\mathrm{ABS}}{\varepsilon}=-\frac{\Delta H}{R T}+\frac{\Delta S}{R} \ln \left(\frac{\left[D_{0}-\mathrm{ABS}\right]}{\varepsilon}\right) \ln \left(\frac{\left[A_{0}-\mathrm{ABS}\right]}{\varepsilon}\right) .
$$

The slope of the plot was used to calculate enthalpies $\left(\Delta H^{\circ}\right)$ and relative entropies $\left(\Delta S^{\circ}\right)$ from the intercept of the plot and shown in Figure 4.

$\Delta G^{\circ}$ values of the complexes were calculated from Gibbs free energy of formation according to the equation given below:

$$
\Delta G^{\circ}=-R T \ln K_{\mathrm{CT}},
$$

where $\Delta G^{\circ}$ is the free energy of the charge transfer complexes; $R$, the gas constant $\left(1.987 \mathrm{cal} \mathrm{mol}^{-1{ }^{\circ}} \mathrm{C}\right) ; T$, the temperature in Kelvin degrees; $K_{\mathrm{CT}}$, the association constant of donoracceptor complexes $\left(\mathrm{Lmol}^{-1}\right)$. The $\Delta H^{\circ}, \Delta S^{\circ}$, and $\Delta G^{\circ}$ values of the complexes are given in Table 2.

The obtained results reveal that the CT complex formation process is exothermic and spontaneous. There is a good agreement with the literature values of the constants. When 
TABLE 1: Formation constants of the complexes of mirtazapine with TCNE, TCNQ, DDQ in dichloromethane at $21^{\circ} \mathrm{C}$.

\begin{tabular}{lcccc}
\hline Acceptors-drug & $K_{\mathrm{CT}}\left(\mathrm{L} \cdot \mathrm{mol}^{-1}\right)$ & Stoichiometry & $r^{2}$ & \multicolumn{2}{c}{$\lambda$ max $(\mathrm{nm})$} \\
\hline TCNE & 111 & $1: 1$ & 0.999 & 418 \\
DDQ & 199 & $1: 1$ & 0.998 & 708 \\
TCNQ & 220 & $1: 1$ & 0.996 & 850 \\
\hline
\end{tabular}

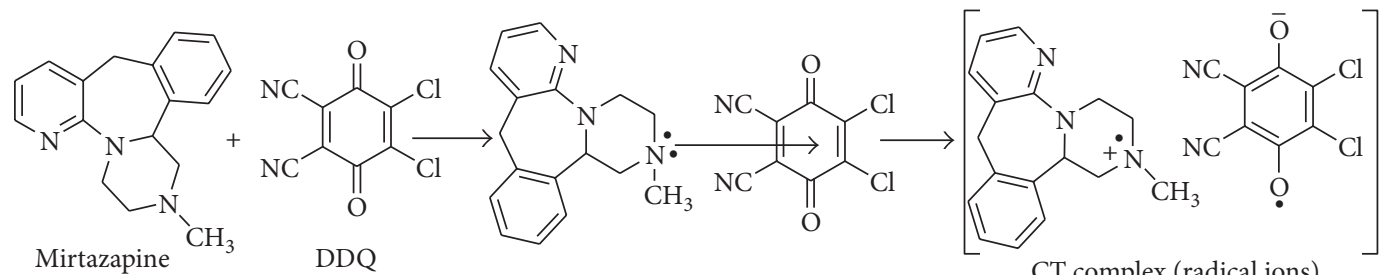

CT complex (radical ions)

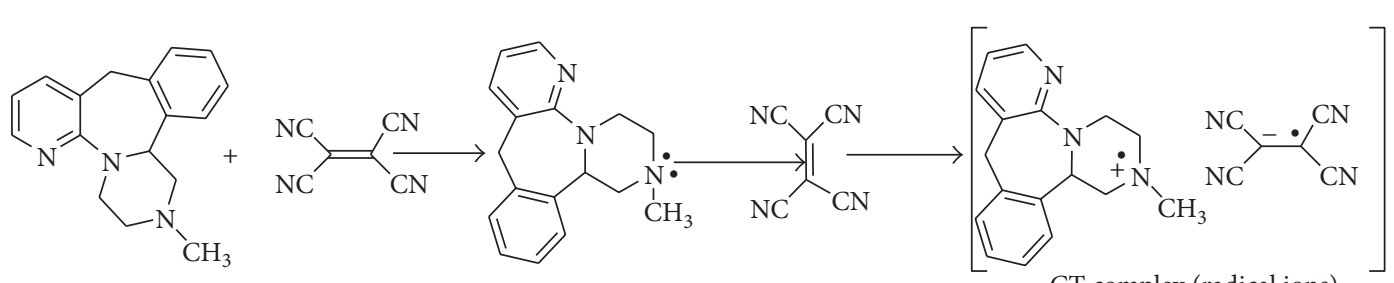
TCNE

CT complex (radical ions)

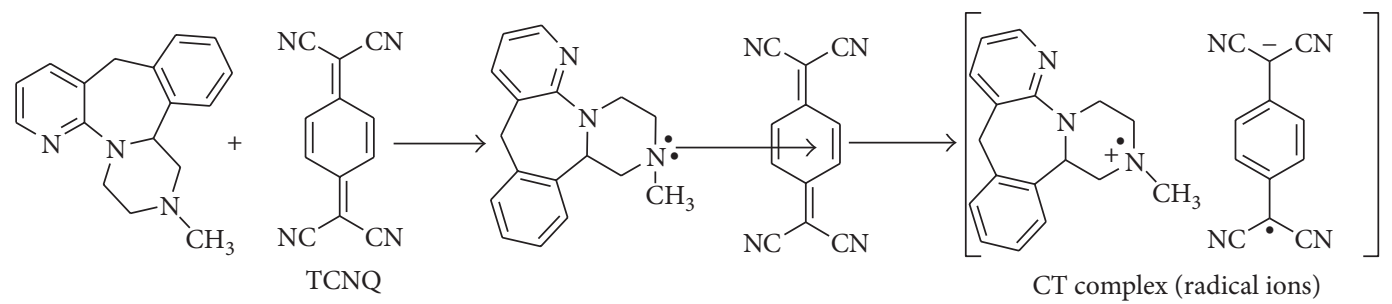

Scheme 3: The molecular structures of compounds and charge transfer transition between donor and acceptors.

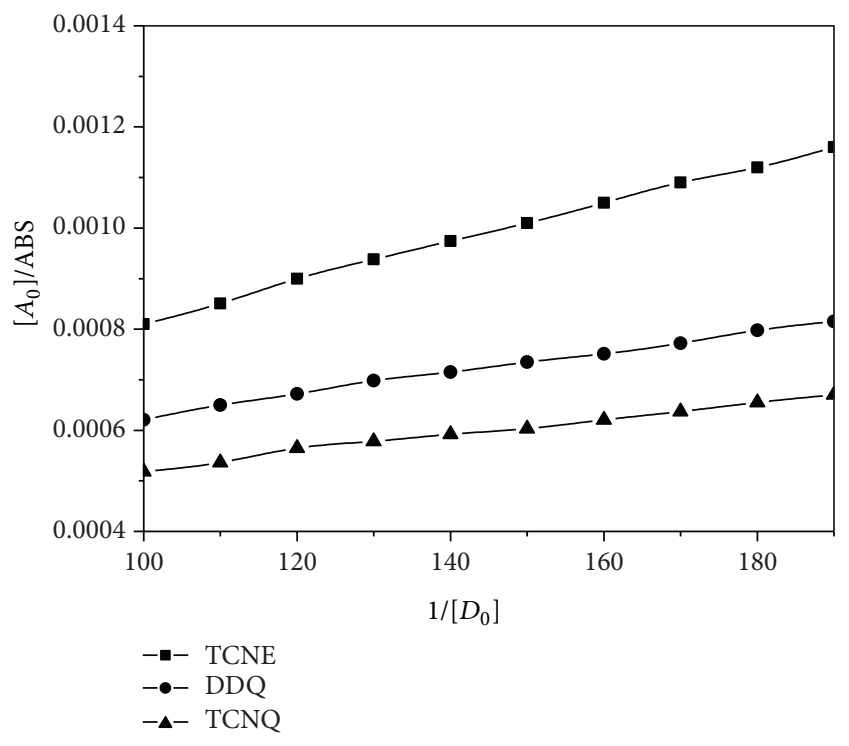

FIGURE 3: Benesi-Hildebrand plots for mirtazapine with TCNE (+), $\operatorname{DDQ}(\Delta)$, and TCNQ $(\mathrm{O})$.

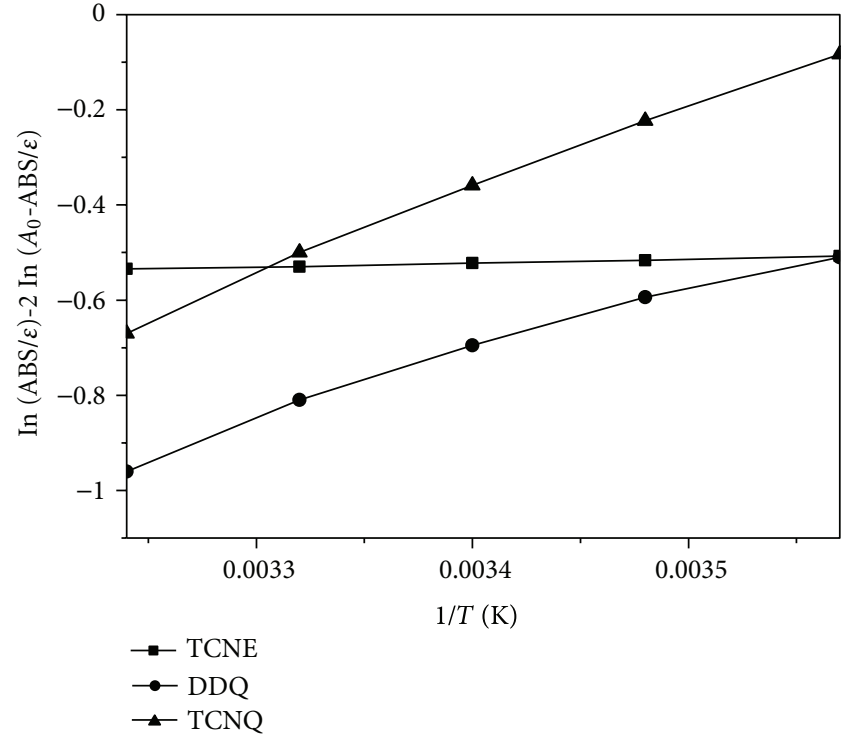

FIGURE 4: Van't Hoff plot for mirtazapine with TCNE (+), DDQ $(\Delta)$, and TCNQ $(\mathrm{O})$ at $7,14,21,28$, and $35^{\circ} \mathrm{C}$. 
TABLE 2: Thermodynamic parameters of the complexes of mirtazapine with TCNE, DDQ, and TCNQ in dichloromethane at $7,14,21,28$, $35^{\circ} \mathrm{C}$ for $\Delta S^{\circ}, \Delta H^{\circ}$ and $21^{\circ} \mathrm{C}$ for $\Delta G^{\circ}$.

\begin{tabular}{|c|c|c|c|c|}
\hline Acceptors drug & $\Delta H^{\circ}\left(\mathrm{cal} \mathrm{mol}^{-1}\right)$ & $\Delta S^{\circ}(\mathrm{Eu})$ & $\Delta G^{\circ}\left(\mathrm{cal} \mathrm{mol}^{-1}\right)$ & $r^{2}$ \\
\hline TCNE & -467 & -164 & -2751 & 0.996 \\
\hline DDQ & -3134 & -2718 & -3092 & 0.990 \\
\hline TCNQ & -3751 & -3536 & -3151 & 0.997 \\
\hline
\end{tabular}

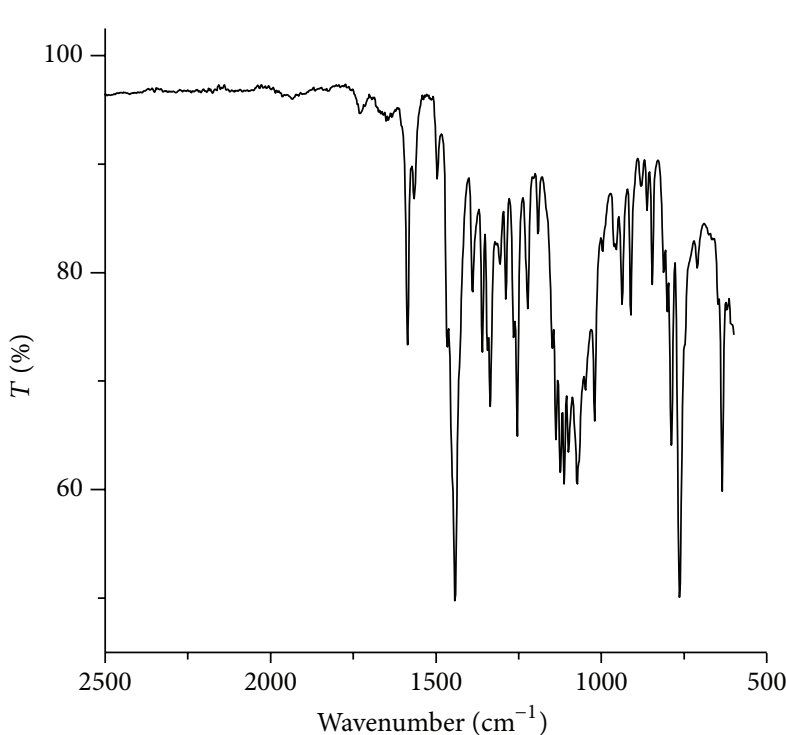

(a)

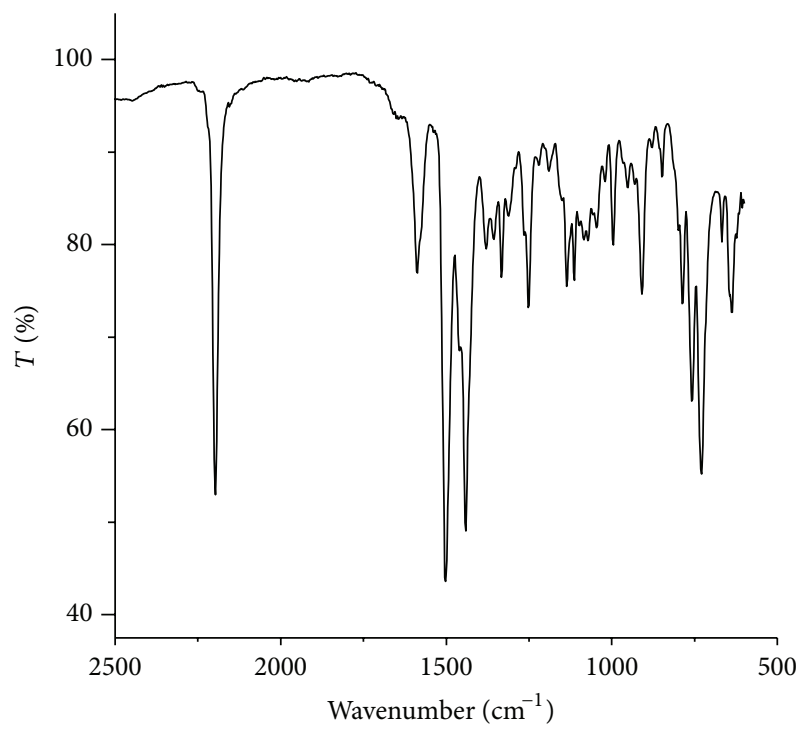

(c)

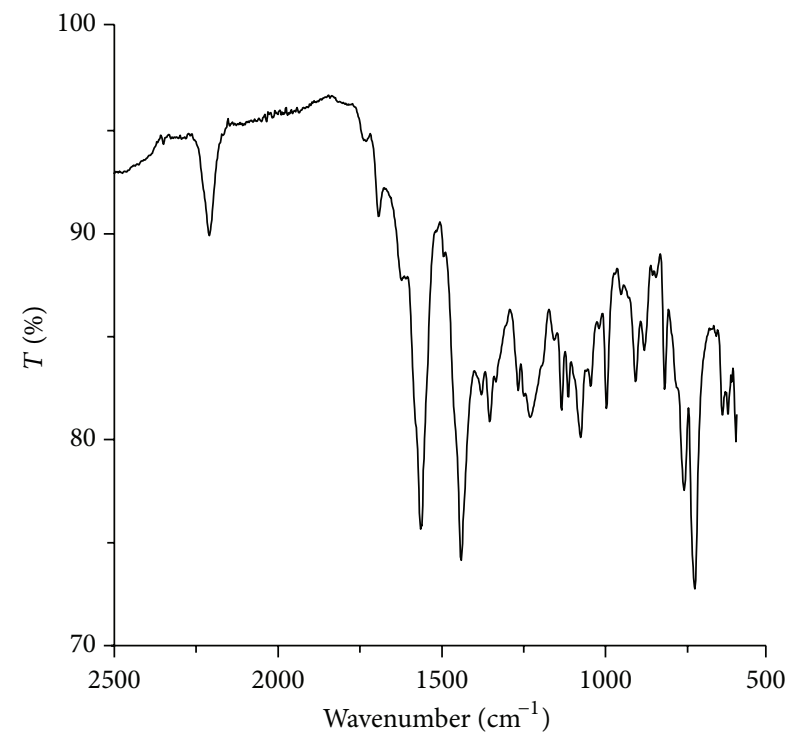

(b)

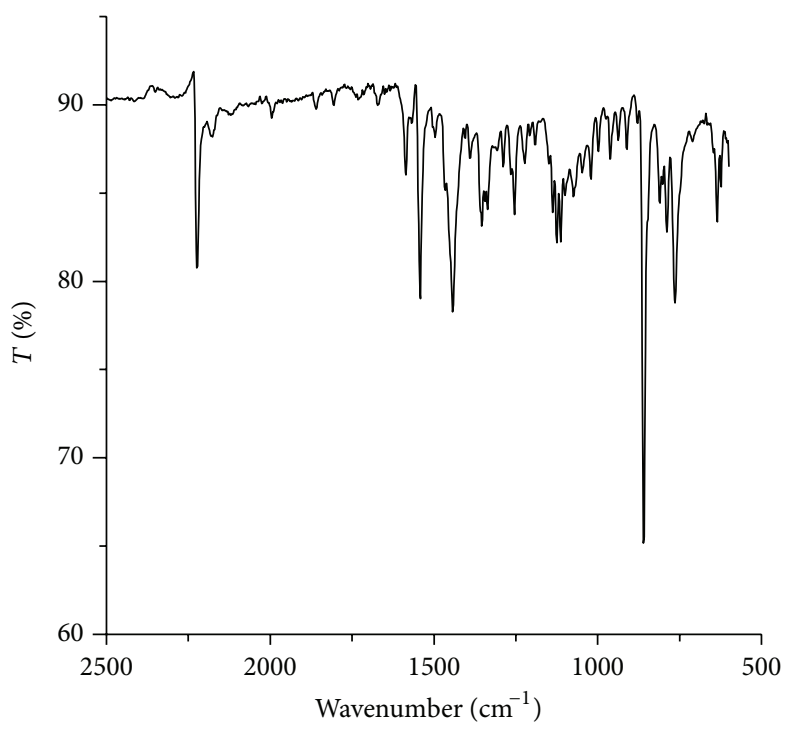

(d)

FIGURE 5: FTIR spectra of mirtazapine (a), mirtazapine-DDQ CT complex (b), mirtazapine-TCNE CT complex (c), mirtazapine-TCNQ CT complex (d) in the range $4000-600 \mathrm{~cm}^{-1}$.

increasing electron affinity of acceptors, the values of the constants increases [27].

Infrared spectra of the electron donor (mirtazapine) and its CT complexes with using acceptors such as TCNE, DDQ, and TCNQ are shown in Figure 5. In the spectra of the CT complexes, each spectrum shows almost the main characteristic bands for both the donor and acceptor in each case. This observation strongly supports the formation of the CT interactions between donor and acceptors. However, the bands of the donor and acceptors in these complexes reveal small shifts in both band intensities and wavenumber values from those of the free molecules. This is normal due to the expected changes of molecular symmetries and electronic structures of the reactants upon complexation. 


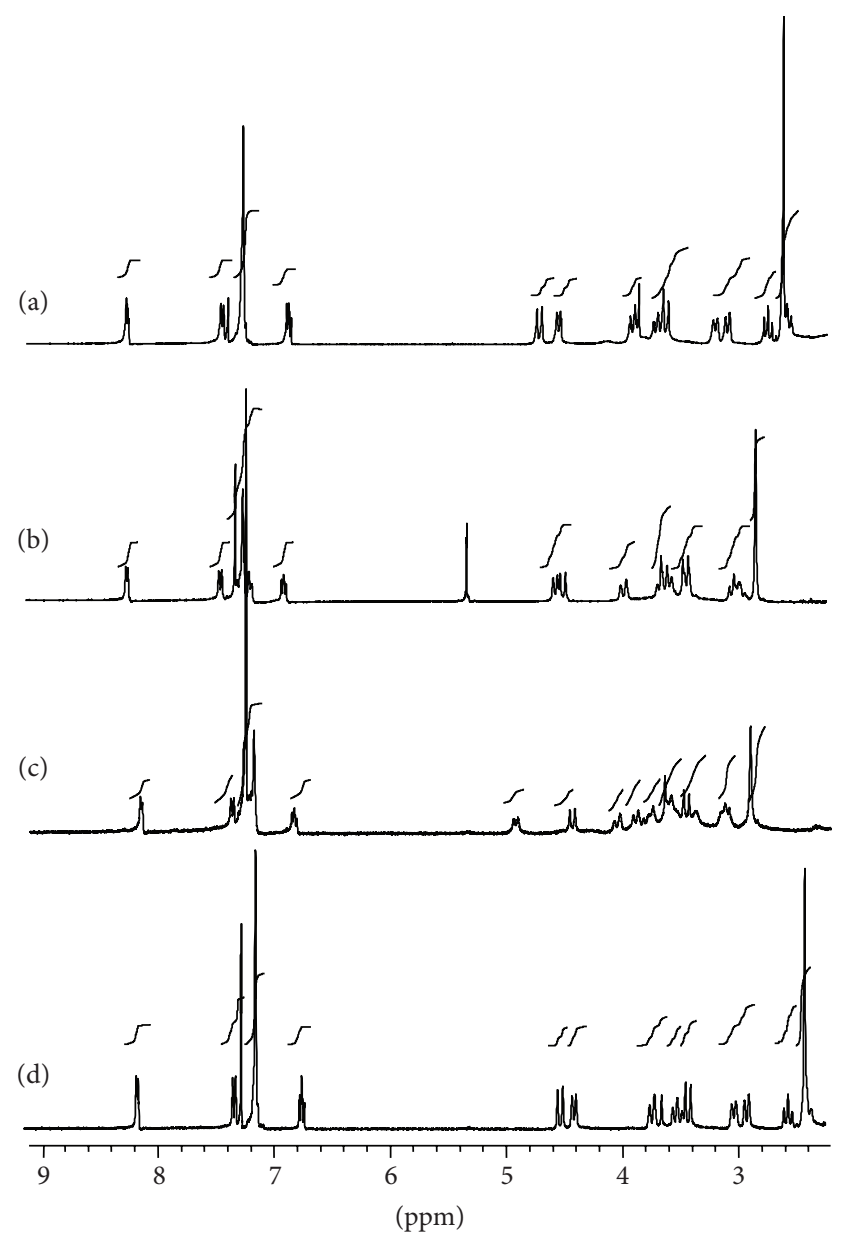

FIgURE 6: ${ }^{1}$ HNMR spectra of mirtazapine (a), mirtazapine-TCNE CT complex (b), mirtazapine-DDQ CT complex (c), mirtazapineTCNQ CT complex (d).

For example, the $v(\mathrm{CN})$ vibrations of TCNE alone are observed as a triplet at 2262,2229 , and $2214 \mathrm{~cm}^{-1}$ and the $v(\mathrm{CN})$ vibrations of DDQ and TCNQ alone are observed at $2223 \mathrm{~cm}^{-1}$ and $2234 \mathrm{~cm}^{-1}$, respectively. These vibrations occur at 2196, 2210, and $2193 \mathrm{~cm}^{-1}$ after complexation by mirtazapine-TCNE, mirtazapine-DDQ, and mirtazapineTCNQ, respectively. Similar changes are also observed for the $v(\mathrm{C}=\mathrm{C})$ vibrations for each $\pi$-acceptors (TCNE, DDQ, and TCNQ) upon complexation. The $v(\mathrm{C}=\mathrm{C})$ of alone TCNE is $1502 \mathrm{~cm}^{-1}$ shifted to $1565 \mathrm{~cm}^{-1}$ upon complexation and the $v(\mathrm{C}=\mathrm{C})$ vibrations after complexation by DDQ and TCNQ were shifted from 1686 to $1565 \mathrm{~cm}^{-1}$ and from 1626 to $1541 \mathrm{~cm}^{-1}$, respectively. The changes of the wavenumber values upon complexation is clearly associated with that the electron donation from mirtazapine is expected to go to the empty $\pi^{*}$ orbitals of acceptors. Same kind of results such as shifting wavenumber values after complexation were observed in the literature $[28,29]$.

${ }^{1}$ HNMR spectra of the electron donor (mirtazapine) and its CT complexes with using acceptors such as TCNE, DDQ, and TCNQ are shown in Figure 6. ${ }^{1}$ HNMR of mirtazapine and the formed CT complexes were carried out in $\mathrm{CDCl}_{3}$. The
${ }^{1} \mathrm{HNMR}$ spectrum of mirtazapine shows the proton on $\mathrm{C} 14 \mathrm{~b}$ of piperazine ring of mirtazapine at $\delta 3.38 \mathrm{ppm}$ as a dublet. In the ${ }^{1}$ HNMR spectrum of mirtazapine-TCNE complex, the peak was shifted to $\delta 3.97 \mathrm{ppm}$ as dublet. The ${ }^{1} \mathrm{HNMR}$ spectrum of mirtazapine-DDQ complex, the peak was found at $\delta 4.05 \mathrm{ppm}$ as dublet. Similarly, the ${ }^{1} \mathrm{HNMR}$ spectrum of mirtazapine shows methylene protons on $\mathrm{C} 10$ of azepine ring in structure of mirtazapine at $\delta 4.54-4.49$ and $4.36-4.32 \mathrm{ppm}$ as dublet-dublet. In the ${ }^{1}$ HNMR spectrum of mirtazapineTCNE complex, these peaks were found between $\delta 4.56$ and $4.46 \mathrm{ppm}$ as one within the other. By studying the ${ }^{1} \mathrm{HNMR}$ spectrum of mirtazapine-DDQ complex, these peaks were found at $\delta 4.87-4.91$ and $4.42-4.46 \mathrm{ppm}$ as dublet-dublet. The ${ }^{1}$ HNMR spectrum of mirtazapine-TCNQ complex shows similar results. Likewise, peaks of other methylene protons are shifted down field to higher ppm values and it confirms clearly that charge transfer complexes were formed.

\section{Conclusions}

In conclusion, the spectroscopic methods have advantage of being simple, sensitive, accurate, and suitable for routine analysis in laboratories. The methods used here are a singlestep reactions and single solvent. Dichloromethane was used here as a solvent to avoid any interactions of solvent with donor and acceptors. The methods can be used as general methods for the spectrophotometric determination of drugs in bulk powder and in commercial formulations.

\section{Conflict of Interests}

The authors declare that they have no conflict of interests.

\section{Acknowledgments}

This work was supported by Sakarya University Scientific Research Foundation (Project no. BAP 2010-02-04-013). The authors thank Santa Farma Drug Company for mirtazapine tablets as Remeron Drage.

\section{References}

[1] E. Dursun, A. Akpinar, and B. Battal, "Sudden hearing loss associated with mirtazapine therapy: a case report," Bulletin of Clinical Psychopharmacology, vol. 19, no. 4, pp. 417-419, 2009.

[2] D. V. N. Srinivasa Rao, R. Dandala, V. K. Handa, M. Sivakumaran, A. V. Raghava Reddy, and A. Naidu, "Improved synthesis of mirtazapine," Organic Preparations and Procedures International, vol. 39, no. 4, pp. 399-402, 2007.

[3] H. V. Wikström, M. M. Mensonides-Harsema, T. I. F. H. Cremers, E. K. Moltzen, and J. Arnt, "Synthesis and pharmacological testing of 1,2,3,4,10,14b-hexahydro-6-methoxy-2methyldibenzo[c,f]pyrazino[1,2-a]azepin and its enantiomers in comparison with the two antidepressants mianserin and mirtazapine," Journal of Medicinal Chemistry, vol. 45, no. 15, pp. 3280-3285, 2002.

[4] Y. AğargünM and S. Ebrinç, "Mirtazapine: a review," Klinik Psikofarmakoloji Bülteni, vol. 8, pp. 59-68, 1998. 
[5] S. H. Abbasi, H. Behpournia, A. Ghoreshi et al., "The effect of mirtazapine add on therapy to risperidone in the treatment of schizophrenia: a double-blind randomized placebo-controlled trial," Schizophrenia Research, vol. 116, no. 2-3, pp. 101-106, 2010.

[6] M. E. El-Zaria, "Spectrophotometric study of the charge transfer complexation of some porphyrin derivatives as electron donors with tetracyanoethylene," Spectrochimica Acta A, vol. 69, no. 1, pp. 216-221, 2008.

[7] M. S. Refat and N. M. El-Metwally, "Investigation of charge transfer complexes formed between 3,3'-dimethylbenzidine (o-toluidine) donor and DDQ, Mp-chloranil and TCNQ as $\pi$-acceptors," Chinese Science Bulletin, vol. 56, no. 19, pp. 1993-2000, 2011.

[8] M. Pandeeswaran and K. P. Elango, "Spectroscopic studies on the interaction of cimetidine drug with biologically significant $\sigma$ - and $\pi$-acceptors," Spectrochimica Acta A, vol. 75, no. 5, pp. 1462-1469, 2010.

[9] M. S. Refat, L. A. El-Zayat, and O. Z. Yeşilel, "Spectroscopic characterization of charge-transfer complexes of morpholine with chloranilic and picric acids in organic media: crystal structure of bis(morpholinium 2,4,6-trinitrocyclohexanolate)," Spectrochimica Acta A, vol. 75, no. 2, pp. 745-752, 2010.

[10] F. P. Flá, J. Palou, R. Valero, C. D. Hall, and P. Speers, "Kinetics and mechanism of the addition of triphenylphosphoniocyclopentadienide to tetrachloro-p-benzoquinone," Journal of the Chemical Society, Perkin Transactions 2, no. 12, pp. 1925-1932, 1991.

[11] M. S. Refat, S. A. El-Korashy, I. M. El-Deen, and S. M. El-Sayed, "Charge-transfer complexes of sulfamethoxazole drug with different classes of acceptors," Journal of Molecular Structure, vol. 980, no. 1-3, pp. 124-136, 2010.

[12] R. Foster, Organic Charge Transfer Complexes, Academic Press, London, UK, 1969.

[13] A. Korolkovas, Essentials of Medical Chemistry, chapter 3, John Wiley \& Sons, New York, NY, USA, 2nd edition, 1998.

[14] K. Takahasi, K. Horino, T. Komura, and K. Murata, "Photovoltaic properties of porphyrin thin films mixed with ochloranil," Bulletin of the Chemical Society of Japan, vol. 66, no. 3, pp. 733-738, 1993.

[15] S. M. Andrade, S. M. B. Costa, and R. Pansu, "Structural changes in W/O Triton X-100/cyclohexane-hexanol/water microemulsions probed by a fluorescent drug Piroxicam," Journal of Colloid and Interface Science, vol. 226, no. 2, pp. 260-268, 2000.

[16] A. M. Slifkin, Charge-Transfer Interaction of Biomolecules, Academic Press, New York, NY, USA, 1971.

[17] F. M. Abou Attia, "Use of charge-transfer complex formation for the spectrophotometric determination of nortriptyline," Farmaco, vol. 55, no. 11-12, pp. 659-664, 2000.

[18] F. Yakuphanoglu and M. Arslan, "Determination of thermooptic coefficient, refractive index, optical dispersion and group velocity parameters of an organic thin film," Physica B, vol. 393, no. 1-2, pp. 304-309, 2007.

[19] F. Yakuphanoglu, M. Arslan, M. Kucukislamoglu, and M. Zengin, "Temperature dependence of the optical band gap and refractive index of poly(ethylene terepthalate) oligomer-DDQ complex thin film," Solar Energy, vol. 79, no. 1, pp. 96-100, 2005.

[20] M. Arslan and H. Duymus, "Spectroscopic studies of charge transfer complexes between colchicine and some $\pi$ acceptors," Spectrochimica Acta A, vol. 67, no. 3-4, pp. 573-577, 2007.
[21] M. Arslan, J. Masnovi, and R. Krafcik, "Charge-transfer complex formation between $\mathrm{p}$-chloranil and 1, $n$-dicarbazolylalkanes," Spectrochimica Acta A, vol. 66, no. 4-5, pp. 1063-1067, 2007.

[22] H. Duymus, M. Arslan, M. Kucukislamoglu, and M. Zengin, "Charge transfer complex studies between some nonsteroidal anti-inflammatory drugs and $\pi$-electron acceptors," Spectrochimica Acta A, vol. 65, no. 5, pp. 1120-1124, 2006.

[23] R. Job, Advanced Physicochemical Experiments, Pitman, London, UK, 1964.

[24] M. Stolka, J. F. Yanus, and J. M. Pearson, "Polymerization of vinylanthracene monomers. 3.1- and 9-vinylanthracenes," Macromolecules, vol. 9, no. 5, pp. 715-719, 1976.

[25] H. A. Benesi and J. H. Hildebrand, "A spectrophotometric investigation of the interaction of iodine with aromatic hydrocarbons," Journal of the American Chemical Society, vol. 71, no. 8, pp. 2703-2707, 1949.

[26] A. Mostafa and H. S. Bazzi, "Charge-transfer complexes of 1(2-aminoethyl) piperazine with $\sigma$-And $\pi$-acceptors," Journal of Molecular Structure, vol. 983, no. 1-3, pp. 153-161, 2010.

[27] E. H. El-Mossalamy, "Molecular spectroscopic studies of charge transfer complexes of thiourea derivatives with benzoquinones," Journal of Molecular Liquids, vol. 123, no. 2-3, pp. 118-123, 2006.

[28] S. Y. AlQaradawi, H. S. Bazzi, A. Mostafa, and E. M. Nour, "Synthesis, spectroscopic and thermal investigations of solid chargetransfer complexes of 1,4,7-trimethyl-1,4,7-triazacyclononane and the acceptors iodine, TCNE, TCNQ and chloranil," Spectrochimica Acta A, vol. 71, no. 4, pp. 1594-1598, 2008.

[29] E. M. Nour, S. Y. Alqaradawi, A. Mostafa, E. Shams, and H. S. Bazzi, "Synthesis, characterization and spectroscopic structural studies of charge-transfer complexes of 1,4,8,11tetraazacyclotetradecane-5,7-dione with iodine, TCNE and DDQ," Journal of Molecular Structure, vol. 980, no. 1-3, pp. 218-224, 2010. 

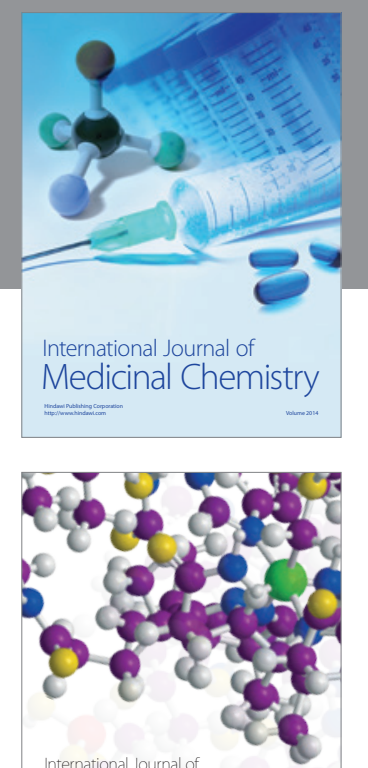

\section{Carbohydrate} Chemistry

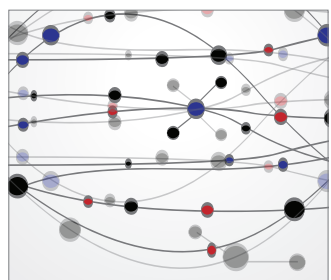

The Scientific World Journal
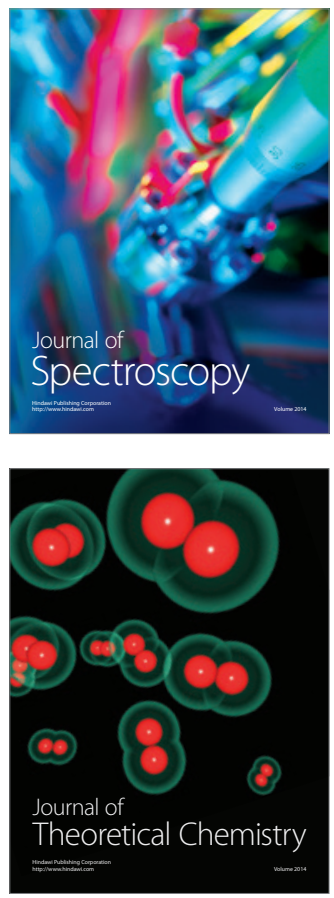
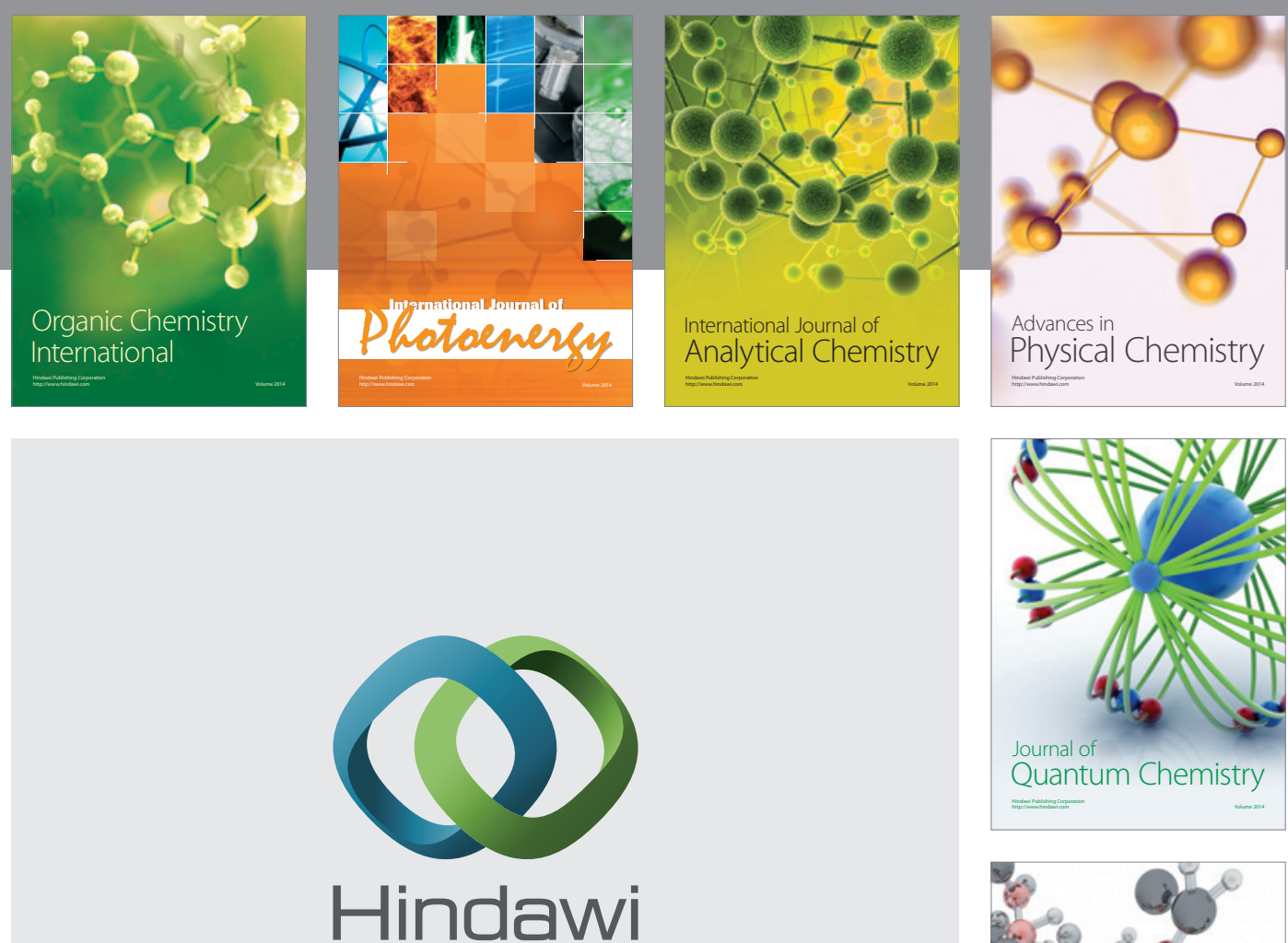

Submit your manuscripts at

http://www.hindawi.com

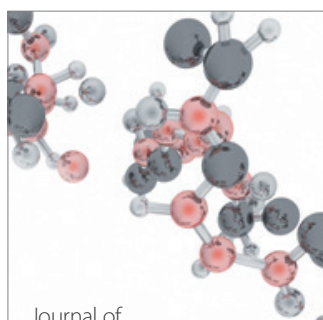

Analytical Methods

in Chemistry

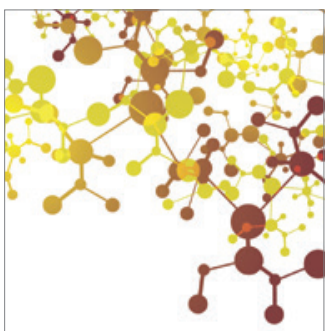

Journal of

Applied Chemistry

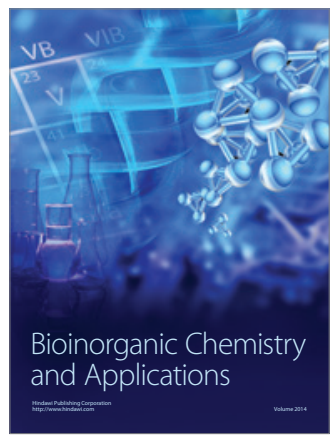

Inorganic Chemistry
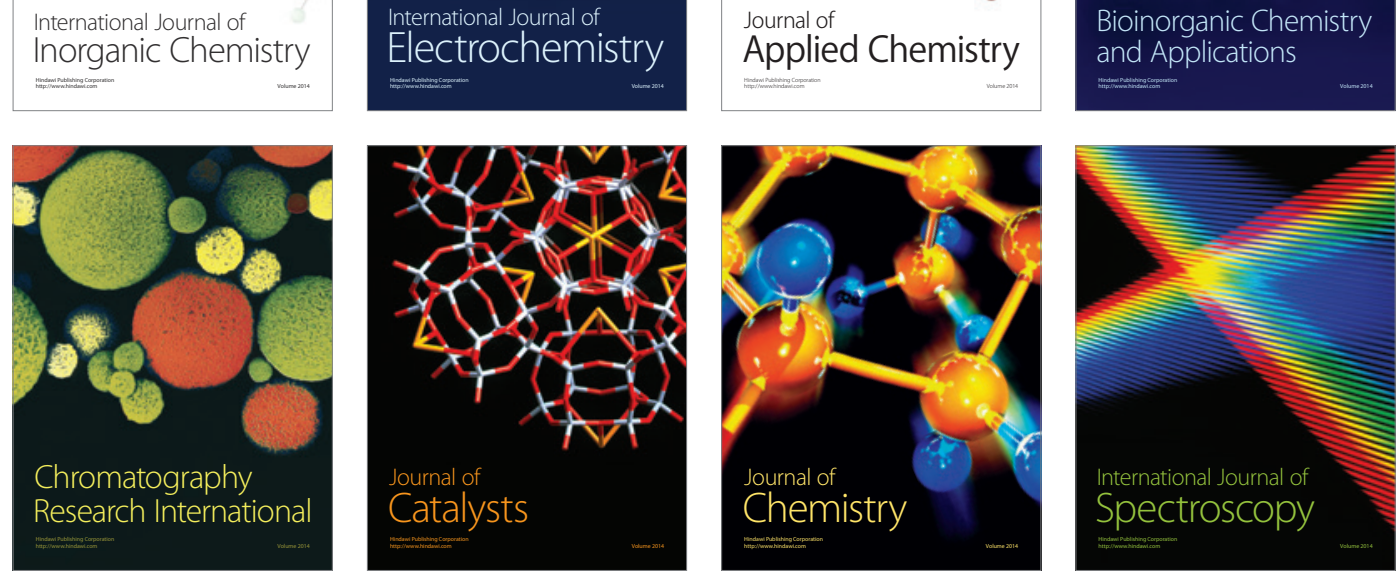